\title{
P54 THREE YEARS OF LIVING WITH GRIEF - REVIEWING A SERIES OF MEETINGS FOR PEOPLE WHO HAVE BEEN BEREAVED
}

Una Smale, Simon Spence Highland Hospice, Inverness, Scotland

10.1136/bmjspcare-2011-000105.54

Introduction Highland Hospice Bereavement Support Service offers varied support to individuals and families. For the past 3 years, in order to widen the support options available and recognising people's differing needs, we have been offering Living With Grief, a time limited group-based support.

The current programme consists of:

- Weekly sessions of $2 \mathrm{~h}$ duration, offered over an 8 week period.

- Groups co-facilitated by two staff members; both accredited counsellors, with extensive group work experience.

- Group membership mixed in circumstances of bereavement, age, gender and ethnic/cultural background.

- 'Closed' group membership; all members attending all meetings.

Aim To review the development of the Living With Grief programme. Particular attention is paid to how the programme has adapted in response to both feedback from the participants and the facilitators' experience.

\section{Method}

- Review the current provision.

- Review participant evaluation over the 3 year period.

- Review facilitator experiences.

- Review changes already made as a result of this feedback and evaluation.

\section{Results}

- The programme has changed significantly over the 3 year period.

- The changes have resulted from participant feedback and facilitator experience.

- Feedback from later participants confirmed the desirability of the earlier changes and suggests a constructive dialectic process of development.

As a result of this project review we plan to continue offering Living With Grief as a regular feature of the Highland Hospice Bereavement Service. The findings and recommendations from this review will be of interest to other hospices involved in developing and/or reviewing group support provision in bereavement services. 